\title{
Metabolic Changes during Acclimation and Hardening to Heat and Drought Stress in Zaprionus indianus
}

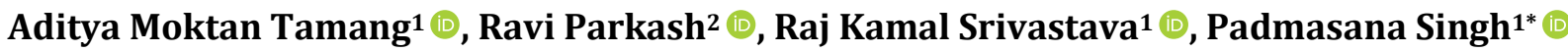 \\ ${ }^{1}$ Department of Zoology, Indira Gandhi National Tribal University, Amarkantak, India \\ ${ }^{2}$ Department of Genetics, Maharshi Dayanand University, Rohtak, India \\ Email: *padmasana.singh@igntu.ac.in
}

How to cite this paper: Tamang, A.M., Parkash, R., Srivastava, R.K. and Singh, P. (2022) Metabolic Changes during Acclimation and Hardening to Heat and Drought Stress in Zaprionus indianus. Advances in Entomology, 10, 110-133.

https://doi.org/10.4236/ae.2022.101009

Received: December 14, 2021

Accepted: January 23, 2022

Published: January 26, 2022

Copyright ( $\odot 2022$ by author(s) and Scientific Research Publishing Inc. This work is licensed under the Creative Commons Attribution International License (CC BY 4.0).

http://creativecommons.org/licenses/by/4.0/

\begin{abstract}
The survival ability of insects can be limited with the changes in the levels of energy metabolites under stressful conditions but only a few studies have considered the plastic effects of heat and related climatic factors relevant to tropical habitats. The objectives of our study were to determine whether adults of Zaprionus indianus are capable of rapid heat hardening (RHH) and rapid desiccation hardening $(\mathrm{RDH})$ and to compare its benefits with heat acclimation (HA) and desiccation acclimation (DA). Adult flies reared under season-specific simulated conditions were subjected to $38^{\circ} \mathrm{C}$ for $\mathrm{RHH}$ and $32^{\circ} \mathrm{C}$ for HA, while $5 \%$ relative humidity (RH) was maintained for $\mathrm{RDH}$ and $40 \% \mathrm{RH}$ for DA. Stress-induced effects of heat and desiccation on the levels of five metabolites namely cuticular lipids (CL), total body lipids (TBL), protein, proline, and carbohydrates were then estimated by biochemical method. Different duration of heat hardening and acclimation led to more accumulation of CL whereas different durations of desiccation hardening and acclimation revealed less accumulation. In contrast, there was an accumulation of carbohydrates and protein under desiccation hardening and acclimation whereas there was the utilization of carbohydrates and protein under heat hardening and acclimation. However, mixed results were observed on the level of proline and TBL under both heat and desiccation stress. These stress-triggered changes in the levels of various metabolites suggest a possible link between heat and desiccation tolerance. Hence, these compensatory changes in the level of various metabolites also suggest possible energetic homeostasis in $Z$. indianus living under harsh climatic conditions of heat and drought in tropical regions.
\end{abstract}

\section{Keywords}

Zaprionus indianus, Rapid Heat Hardening, Heat Acclimation, Rapid 
Desiccation Hardening, Desiccation Acclimation

\section{Introduction}

Climatic changes force the ectotherms to adapt to environmental stress by changing their fundamental physiological functions such as locomotion, development, and reproduction. Tropical insects are likely to exhibit plastic changes of energy metabolites to encounter warmer and drier environments [1]. They accumulate or conserve the existing energy resources by lowering the metabolic rates to survive under harsh climatic stress [2]. Therefore, a physiological mechanism is involved for the survival of these insects under such conditions that include the accumulation and utilization of various energy metabolites to attain energetic homeostasis [3]. Utilization of various energy metabolites like carbohydrates, body lipids, and proteins have been reported in different insects under single or multiple bouts of cold, desiccation, or starvation stress [4] [5] [6] [7].

Under harsh climatic conditions across seasonally varying environments, the insect taxa have displayed the capability to survive through both developmental and adult acclimation to various stressors [2] [8] [9]. They increase stress resistance by hardening or acclimation to stressors like heat or cold or desiccation [3] [10] [11]. Acclimatization of ectothermic organisms under natural environments involves the joint impact of multiple stressors [12] [13]. In order to cope with multiple climatic stresses, insects either accumulate energy metabolites or conserve existing resources through reduced metabolic rates [2]. Thus, the survival of insects under stressful environments is associated with attaining energetic homeostasis against metabolic perturbations caused by multiple stressors [3]. Rajamohan and Sinclair (2009) [14] have reported in their studies that it is hardening which is of more ecological relevance as compared to acclimation for the short-lived life stages such as the larvae of $D$. melanogaster.

The energy metabolism has a dominant role in the survival of diverse insect taxa under stressful conditions that they experience in their lifetime [1]. Several studies have revealed the accumulation and utilization of carbohydrates being linked with cold and drought hardening and/or acclimation of D. melanogaster [15], Belgica antarctica [5] [6] [16] and in D. immigrans [17]. The utilization of body lipids under starvation is well known in drosophilids [18], American dog tick [7], and many other species of insects [19]. Therefore, if cold stress is able to bring changes in the levels of energy metabolites, we may expect similar energy metabolites changes in the insect taxa of the tropical regions during heat and drought stresses.

Several studies in overwintering insects have reported significant changes in the level of energy metabolites, cryoprotectants, and osmoprotectants due to cold stress [4] [20] [21] [22]. In cold hardened or acclimated adults and larvae of $D$. melanogaster, changes in the levels of sugars, free amino acids, and several other 
metabolites have been observed based on metabolomics studies [22] [23] [24]. But, the effects on the level of various energy metabolites due to hardening or acclimation of stressors such as heat and desiccation have not been thoroughly studied in the tropical species of Drosophila so far. Zaprionus indianus is a native species to the Afro-tropical region that has now invaded various parts of the world. In India, this species was first described by J.P. Gupta in 1970. Although it feeds mainly upon yeasts and bacteria on decomposing fruits, it has also been reported as a pest in many parts of the world. In Brazil, $Z$. indianus is being considered a primary pest to fig plants [25]. The genetic background of $Z$. indianus in India may be different as compared to its genetic diversity in its native place. In the present work, we wanted to study the changes in the level of different metabolites due to heat and desiccation hardening or acclimation in $Z$. indianus. We hypothesized that some metabolites may show many fold changes in response to heat and desiccation hardening or acclimation which could be further used as key metabolites to monitor changes due to different climatic stressors.

\section{Materials and Method}

\subsection{Collection and Cultures}

Wild flies of Zaprionus indianus ( $\mathrm{n}=450-500$ flies) were collected by net sweeping in dry seasons (April-May $37^{\circ} \mathrm{C}-45^{\circ} \mathrm{C}$ ) from Pendraroad and Gaurella region, Chhattisgarh (Altitude $618 \mathrm{~m}$; Latitude $22.743^{\circ} \mathrm{N}, 81.923^{\circ} \mathrm{E}$ ). Wild-caught flies were reared in laboratory under simulated season-specific thermal and humidity conditions on standard cornmeal-yeast-agar medium. Cultures were maintained close to their ambient $\mathrm{RH}(55 \%)$ as well as ambient $\mathrm{T}_{\text {avg }}\left(27^{\circ} \mathrm{C}\right)$ in the BOD chambers. All the experiments were performed in laboratory reared flies within first two generations after the wild collection. For all cultures, larval density was kept low by limiting the egg-laying period to $8 \mathrm{~h}$ which resulted in 40 60 eggs per vial $(37 \times 100 \mathrm{~mm}$ size $)$. Furthermore, all the assays were performed on 8 day-old virgin flies. Virgin flies were collected from newly eclosed flies within $1.5 \mathrm{~h}$ intervals using mild anesthesia. Flies were sexed simultaneously based upon their genitalia and both sexes were kept in separate vials.

\subsection{Metric Traits (Body Size)}

We measured wet body weight and dry body weight in flies $(\mathrm{n}=30)$ reared under simulated season-specific thermal $\left(27^{\circ} \mathrm{C}\right)$ and humidity conditions $(55 \%$ $\mathrm{RH})$. The wet body weight of an individual fly was measured on a Sartorius microbalance (Model-CPA26P; https://www.sartorius.com/en). For dry mass, individual flies were dried at $60^{\circ} \mathrm{C}$ and weighed on Sartorius microbalance. Total water content was measured as the difference between wet and dry mass.

Experimental set-up

\subsection{Rapid Heat Hardening (RHH) and Heat Acclimation (HA)}

For RHH, 8-day old virgin male and female flies reared under simulated sea- 
son-specific thermal $\left(27^{\circ} \mathrm{C}\right)$ and humidity conditions $(55 \% \mathrm{RH})$ were subjected to 1) Control group without treatment (flies reared under simulated season-specific thermal conditions of $27^{\circ} \mathrm{C}$ and humidity conditions of $55 \% \mathrm{RH}$ ); 2) $1 \mathrm{hr}$ of heat at $38^{\circ} \mathrm{C}$; 3) $3 \mathrm{hr}$ of heat at $38^{\circ} \mathrm{C}$. These flies were first transferred to glass tubes with a cotton plug and then kept in a water-bath which was already set at $38^{\circ} \mathrm{C}$. However, for HA virgin male and female flies were transferred to new BOD chambers whose temperature was already set at $32^{\circ} \mathrm{C}$ and they were subjected to 1) Control group without treatment (flies reared under simulated season-specific thermal conditions of $27^{\circ} \mathrm{C}$ and humidity conditions of $55 \% \mathrm{RH}$ ); 2) 7 days old group of flies were kept for 1 day at $32^{\circ} \mathrm{C}$; 3 ) 5 days old group of flies were kept for 3 days at $32^{\circ} \mathrm{C}$. Different aged flies for acclimation treatment were taken so that once the treatment was completed; we were able to get all 8-day old flies for further experiments to be performed.

\subsection{Rapid Heat Hardening (RHH) and Heat Acclimation (HA)}

For $\mathrm{RDH}, 8$-day old virgin male and female flies reared under simulated season-specific thermal $\left(27^{\circ} \mathrm{C}\right)$ and humidity conditions $(55 \% \mathrm{RH})$ were subjected to 1) Control group without treatment (flies reared under simulated season-specific thermal conditions of $27^{\circ} \mathrm{C}$ and humidity conditions of 55\% RH) 2) $1 \mathrm{hr}$ of desiccation at $5 \% \mathrm{RH}$, and 3) $3 \mathrm{hr}$ of desiccation at $5 \% \mathrm{RH}$ by following the double tube method of desiccation set-up. 5 flies per vial were put and then covered with a muslin cloth. In the second vial $2 \mathrm{mg}$ dry powder of $\mathrm{CaCl}_{2}$ was added and finally, the vials containing the flies were attached to it in an inverted manner. These attached tubes were then air-sealed with the help of tape and parafilm [18].

A similar experimental set-up was followed for DA also but with a small change. Instead of $\mathrm{CaCl}_{2}, 2 \mathrm{~mL}$ of saturated Sodium benzoate solution was added which maintained the $\mathrm{RH}$ at $35 \%$. In this setup, the male and female virgin flies were subjected to 1 ) Control group without treatment (flies reared under simulated season-specific thermal conditions of $27^{\circ} \mathrm{C}$ and humidity conditions of 55\% RH) 2) 7 days old group of flies were kept for $20 \mathrm{hr}$ at $35 \%$ $\mathrm{RH}$, and 3) 6 days old group of flies were kept for $40 \mathrm{hr}$ at 35\% RH. Different aged flies for acclimation treatment were taken so that once the treatment was completed; we were able to get all 8-day old flies for further experiments to be performed.

\subsection{Assessment of Cuticular Lipid Mass}

Cuticular lipid mass was assessed $(\mathrm{n}=30)$ in control, heat hardened and acclimated, desiccation hardened and acclimated groups of $Z$. indianus flies from both the sexes. For estimation of cuticular lipid mass, individual flies were dried overnight at $60^{\circ} \mathrm{C}$ to get constant dry mass. Such dried flies were kept in HPLC-grade hexane for $1 \mathrm{hr}$ and thereafter the flies were washed with fresh solvent and they were again dried at $37^{\circ} \mathrm{C}$ and reweighed. Cuticular lipid mass was 
calculated per individual as the difference between initial dry mass and the lipid-free dry mass following the solute extraction. The cuticular lipid content was further normalized to their respective lipid-free dry mass [26].

\subsection{Estimation of Total Body Lipids Content}

Body lipid content was estimated in $(\mathrm{n}=30)$ in control, heat hardened and acclimated, desiccation hardened and acclimated groups of $Z$. indianus flies from both the sexes. For lipid content, individual flies were dried in $2 \mathrm{~mL}$ microcentrifuge tubes (http://www.tarsons.in) at $60^{\circ} \mathrm{C}$ for $48 \mathrm{hr}$ and then weighed on Sartorius microbalance (Model-CPA26P; $0.001 \mathrm{mg}$ precision;

http://www.sartorious.com). Thereafter, $1.5 \mathrm{~mL}$ diethyl ether was added to each microcentrifuge tube and kept for $24 \mathrm{~h}$ under continuous shaking (200 rpm) at $37^{\circ} \mathrm{C}$. Finally, the solvent was removed and individuals were again dried at $60^{\circ} \mathrm{C}$ for $24 \mathrm{~h}$ and reweighed. Calculation of body lipid content was done by subtracting the lipid-free dry mass of individual flies by initial dry mass per fly. The body lipid content was further normalized to their respective lipid-free dry mass [17].

\subsection{Proline Estimation}

We measured proline in flies $(\mathrm{n}=30)$ from control, heat hardened and acclimated, desiccation hardened and acclimated groups of $Z$. indianus flies from both the sexes. Proline concentrations in crude homogenates were determined by the modified method after Bergman and Loxley (1970) [27]. Thirty adult flies were homogenized in $1 \mathrm{~mL}$ of sulfosalicylic acid. Following centrifugation, $50 \mu \mathrm{l}$ of the homogenate was added to $200 \mu \mathrm{l}$ glacial acetic acid and $200 \mu \mathrm{l}$ of ninhydrin solution in a capped tube. The solutions were mixed and incubated for $60 \mathrm{~min}$ at $100^{\circ} \mathrm{C}$. Following incubation, the samples were extracted with toluene, and the absorbance of the aqueous phase was quantified at 520 $\mathrm{nm}$ in reference to a proline standard curve. Standard curve was plotted using different dilutions of proline. In this assay, interfering materials are removed by absorption to the protein-sulphosalicylic acid complex. The extracted proline is made to react with ninhydrin in acidic conditions ( $\mathrm{pH}$ 1.0) to form the chlorophore (red color) which is estimated spectrophotometrically. Proline content was calculated per individual by normalizing the values from the initial body mass.

\subsection{Protein Estimation}

Protein levels were measured using the Bradford method [28]. Protein content was estimated in flies $(n=30)$ from control, heat hardened and acclimated, desiccation hardened and acclimated groups of $Z$. indianus flies from both the sexes. Ten flies were homogenized in $1 \mathrm{~mL}$ of lysis buffer and the homogenate (in $1.5 \mathrm{~mL}$ microcentrifuge tube) was centrifuged at $10,000 \mathrm{rpm}$ for $10 \mathrm{~min}$ at $4^{\circ} \mathrm{C}$ in a Fresco 21 centrifuge (Thermo-Fisher Scientific). Further, $100 \mu \mathrm{L}$ of the sample was mixed with $900 \mu \mathrm{L}$ of Bradford reagent (Sigma-Aldrich). Standard curve was 
plotted using different dilutions of bovine serum albumin. The amount of protein was estimated spectrophotometrically at $595 \mathrm{~nm}$ in reference to this standard curve. The protein level was then normalized with their respective body mass.

\subsection{Carbohydrate Estimation}

We followed Marron et al. (2003) for quantifying carbohydrates in flies $(\mathrm{n}=30)$ from control, heat hardened and acclimated, desiccation hardened and acclimated groups of $Z$. indianus flies from both the sexes. Ten flies were homogenized in $4 \mathrm{~mL}$ double-distilled water and the homogenates were centrifuged at $10,000 \mathrm{rpm}$ for $5 \mathrm{~min}$. Thereafter, $100 \mu \mathrm{L}$ of supernatant from each sample was aliquoted for further analysis. Carbohydrate content in each sample was converted to glucose using $10 \mu \mathrm{L}$ of amyloglucosidase $\left(8 \mathrm{mg} \cdot \mathrm{ml}^{-1}\right.$; Sigma-Aldrich, www.sigmaaldrich.com) and samples were incubated overnight. Finally, the glucose amount was quantified after adding $1 \mathrm{~mL}$ of infinity glucose reagent (Thermo-Fisher Scientific, www.thermofisher.com) to each tube. Standard curve was plotted using different dilutions of glucose. The amount of glucose was estimated spectrophotometrically at $340 \mathrm{~nm}$ in reference to this standard curve. The carbohydrate level was then normalized with their respective body mass.

\subsection{Statistical Analysis}

The differences between the two groups were analyzed statistically by Welch's two-tailed test. One-way and two-way analysis of variance (ANOVA) followed by Bonferroni test was used for comparing more than two groups as mentioned in the figure legends. Statistical analysis to test the normality of the data and all the figures were generated using the GraphPad Prism 9 software (Graphpad Software, LA, CA, USA). Data are represented as mean \pm SEM.

\section{Results}

Phenotypic differences in metric traits (wet weight, dry weight, total water content) and in metabolites (cuticular lipids, carbohydrates, total body protein, total body lipids, proline) for the control groups of males and females $Z$. indianus flies reared under simulated season-specific thermal $\left(27^{\circ} \mathrm{C}\right)$ and humidity conditions $(55 \% \mathrm{RH})$ are given in Table 1. Data are presented as mean \pm SEM in individuals ( $\mathrm{n}=30$ for each trait). The wet weight and the dry weight were significantly ( $\mathrm{p}<0.01$ ) higher in females $(9.30 \%$ and $49.09 \%$ respectively) as compared to the males. The differences in the total water content and cuticular lipids between the males and females were non-significant in the control group of flies. We observed a significantly higher level of proteins $(12.89 \%, \mathrm{p}<0.01)$, total body lipids $(30.27 \%, \mathrm{p}<0.001)$ and proline $(25.49 \%, \mathrm{p}<0.001)$ in females as compared to males. In contrast, we observed a significantly $(\mathrm{p}<0.001)$ higher level of carbohydrates in males $(22.95 \%)$ as compared to females in the control groups of flies. 
Table 1. Phenotypic differences in metric traits (wet weight, dry weight, total water content) and in metabolites (cuticular lipids, carbohydrates, total body protein, total body lipids, proline) in basal value of males and females $Z$. indianus. Data are presented as mean \pm SEM in individuals ( $\mathrm{n}=30$ for each trait) of $Z$. indianus. Levels of significance with Welch's two-tailed test are shown.

\begin{tabular}{ccccc}
\hline Traits & Male $(ふ)$ & Female $(+)$ & $\mathrm{t}$ & $\mathrm{df}$ \\
\hline Wet weight $(\mathrm{mg} / \mathrm{fly})$ & $1.72 \pm 0.04$ & $1.88 \pm 0.05$ & 2.79 & $55.50^{* *}$ \\
Dry weight $(\mathrm{mg} / \mathrm{fly})$ & $0.55 \pm 0.01$ & $0.82 \pm 0.02$ & 9.92 & $43.711^{* * *}$ \\
Total water content $(\mathrm{mg} / \mathrm{fly})$ & $1.17 \pm 0.05$ & $1.06 \pm 0.04$ & 1.81 & $57.40 \mathrm{~ns}$ \\
${ }^{*}$ Cuticular Lipids $\left(\mu \mathrm{g} \mathrm{mg}^{-1} \mathrm{fly}^{-1}\right)$ & $11.12 \pm 0.43$ & $11.10 \pm 0.91$ & 0.02 & $41.26 \mathrm{~ns}$ \\
${ }^{\$}$ Carbohydrates $\left(\mu \mathrm{g} \mathrm{m}^{-1} \mathrm{fly}^{-1}\right)$ & $150.00 \pm 2.65$ & $122.00 \pm 2.02$ & 8.41 & $54.18^{* * *}$ \\
${ }^{\$}$ Total body protein $\left(\mu \mathrm{g} \mathrm{mg}^{-1} \mathrm{fly}^{-1}\right)$ & $129.60 \pm 2.90$ & $146.30 \pm 4.33$ & 3.20 & $50.64{ }^{* *}$ \\
${ }^{*}$ Total body lipids $\left(\mu \mathrm{g} \mathrm{mg}{ }^{-1} \mathrm{fly}^{-1}\right)$ & $100.10 \pm 2.89$ & $130.40 \pm 1.96$ & 8.70 & $51.08^{* * *}$ \\
${ }^{\$}$ Total body proline $\left(\mu \mathrm{g} \mathrm{mg}^{-1} \mathrm{fly}^{-1}\right)$ & $8.04 \pm 0.22$ & $10.09 \pm 0.18$ & 7.28 & $55.49^{* * *}$ \\
\hline
\end{tabular}

$\left({ }^{*} \mathrm{p}<0.05 ;{ }^{* *} \mathrm{p}<0.01 ;{ }^{* *} \mathrm{p}<0.001 ; \mathrm{ns}=\right.$ non-significant $) ;{ }^{*}=$ Normalized with their respective dry mass; $\$=$ Normalized with their respective body weight. Welch corrected $t$ and $\mathrm{df}$ values are presented in the table.

\subsection{Differences in Accumulation of Cuticular Lipids (CL) under Heat and Desiccation Stress}

The changes in the level of cuticular lipids in $Z$. indianus flies reared under simulated season-specific conditions subjected to different duration of heat and desiccation hardening and acclimation are shown in Figure 1 and Table 2. For heat stress, flies showing changes in the level of CL during heat hardening and acclimation are shown in Figure 1(a) \& Figure 1(b) respectively. For desiccation stress, flies showing changes in the level of CL during desiccation hardening and acclimation are shown in Figure 1(c) \& Figure 1(d) respectively.

The $Z$. indianus flies when subjected to heat and desiccation stress, showed increase in the level of CL with the increase in duration of heat or desiccation hardening and acclimation. But the increase in the amount of CL during heat hardening and acclimation was more pronounced as compared to their respective controls. During $1 \mathrm{hr}$ RHH, the accumulation of CL was significantly ( $\mathrm{p}<$ 0.001 ) higher in both males (133.72\%) and in females (126.33\%) as compared to their respective controls. Similar results were also observed during $3 \mathrm{hr}$ RHH, showing significant $(\mathrm{p}<0.001)$ increase in CL in both males $(260.07 \%)$ as well as in females $(211.81 \%)$ as compared to their respective controls. During 1day HA, the level of CL increased significantly ( $\mathrm{p}<0.001)$ in both males (124.91\%) and females $(220.19 \%)$ of $Z$. indianus. Further, when the flies were subjected to 3 days HA, the increase in the level of CL was significant ( $\mathrm{p}<$ 0.001 ) in both males (284.35\%) and in females (284.22\%) as compared to their respective controls. 
Table 2. Results of two-way ANOVA showing the effects of adult hardening/acclimation to heat or desiccation stress on various metabolites in male and female $Z$. indianus.

\begin{tabular}{|c|c|c|c|c|c|c|c|c|c|c|c|c|c|c|c|c|c|}
\hline & & \multicolumn{4}{|c|}{ RHH } & \multicolumn{4}{|c|}{ HA } & \multicolumn{4}{|c|}{ RDH } & \multicolumn{4}{|c|}{ DA } \\
\hline & & Sex & Treatment & $S^{*} T$ & Error & Sex & Treatment & $S^{*} T$ & Error & Sex & Treatment & $S^{*} T$ & Error & Sex & Treatment & $S^{*} T$ & Error \\
\hline \multirow{5}{*}{${ }^{*}$ Cuticular Lipi } & $\mathrm{df}$ & 1 & 2 & 2 & 174 & 1 & 2 & 2 & 174 & 1 & 2 & 2 & 174 & 1.0 & 2.0 & 2.0 & 174.0 \\
\hline & & & & & & & & & & & & & & & & & \\
\hline & F & 2.9 & 145.0 & 1.8 & & 11.9 & 336.4 & 12.4 & & 15.5 & 98.6 & 4.9 & & 0.0 & 56.5 & 4.0 & \\
\hline & $\mathrm{p}$ value & ns & $* * *$ & ns & & $* * *$ & $* * *$ & $* * *$ & & $* * *$ & $* * *$ & $* *$ & & $\mathrm{~ns}$ & $* * *$ & * & \\
\hline & $\begin{array}{l}\% \text { of total } \\
\text { variation }\end{array}$ & 0.6 & 61.7 & 0.8 & & 1.3 & 76.2 & 2.8 & & 3.9 & 49.7 & 2.5 & & 0.0 & 38.3 & 2.7 & \\
\hline \multirow{7}{*}{${ }^{\text {s Carbohydrate }}$} & $\begin{array}{l}\text { Sum of } \\
\text { squares }\end{array}$ & 4805.0 & 107310.0 & 23590.0 & 31752.0 & 500.0 & 160570.0 & 13810.0 & 50270.0 & 5120.0 & 23470.0 & 17590.0 & 57532.0 & 25205.0 & 39370.0 & 490.0 & 62596.0 \\
\hline & $\mathrm{df}$ & 1 & 2 & 2 & 174 & 1 & 2 & 2 & 174 & 1 & 2 & 2 & 174 & 1 & 2 & 2 & 174 \\
\hline & Mean square & 4805.0 & 53655.0 & 11795.0 & 182.5 & 500.0 & 80285.0 & 6905.0 & 288.9 & 5120.0 & 11735.0 & 8795.0 & 330.6 & 25205.0 & 19685.0 & 245.0 & 359.7 \\
\hline & & & & & & & & & & & & & & & & & \\
\hline & $\mathbf{F}$ & 26.3 & 294.0 & 64.6 & & 1.7 & 277.9 & 23.9 & & 15.5 & 35.5 & 26.6 & & 70.0 & 54.7 & 0.7 & \\
\hline & $\mathrm{p}$ value & $* * *$ & $* * *$ & $* * *$ & & ns & $* * *$ & $* * *$ & & $* * *$ & $* * *$ & $* * *$ & & $* * *$ & $* * *$ & ns & \\
\hline & $\begin{array}{l}\% \text { of total } \\
\text { variation }\end{array}$ & 2.9 & 64.1 & 14.1 & & 0.2 & 71.3 & 6.1 & & 4.9 & 22.6 & 17.0 & & 19.7 & 30.8 & 0.4 & \\
\hline \multirow{4}{*}{${ }^{s}$ Protein } & $\begin{array}{l}\text { Sum of } \\
\text { squares }\end{array}$ & 877.5 & 92368.0 & 8620.0 & 54944.0 & 12826.0 & 31499.0 & 2880.0 & 58762.0 & 1842.0 & 39677.0 & 2493.0 & 52588.0 & 6024.0 & 76566.0 & 583.7 & 61742.0 \\
\hline & $\mathrm{df}$ & 1 & 2 & 2 & 174 & 1 & 2 & 2 & 174 & 1 & 2 & 2 & 174 & 1 & 2 & 2 & 174 \\
\hline & Mean square & 877.5 & 46184.0 & 4310.0 & 315.8 & 12826.0 & 15749.0 & 1440.0 & 337.7 & 1842.0 & 19839.0 & 1246.0 & 302.2 & 6024.0 & 38283.0 & 291.8 & 354.8 \\
\hline & $\begin{array}{l}\% \text { of total } \\
\text { variation }\end{array}$ & 0.6 & 58.9 & 5.5 & & 12.1 & 29.7 & 2.7 & & 1.9 & 41.1 & 2.6 & & 4.2 & 52.8 & 0.4 & \\
\hline \multirow{6}{*}{$\begin{array}{l}\text { "Total body } \\
\text { lipids }\end{array}$} & $\begin{array}{l}\text { Sum of } \\
\text { squares }\end{array}$ & 31686.0 & 28399.0 & 3589.0 & 49843.0 & 46062.0 & 101092.0 & 359.6 & 33158.0 & 32850.0 & 78660.0 & 959.5 & 41206.0 & 32350.0 & 12572.0 & 2710.0 & 36252.0 \\
\hline & $\mathrm{df}$ & 1 & 2 & 2 & 174 & 1 & 2 & 2 & 174 & 1 & 2 & 2 & 174 & 1 & 2 & 2 & 174 \\
\hline & Mean square & 31686.0 & 14199.0 & 1794.0 & 286.5 & 46062.0 & 50546.0 & 179.8 & 190.6 & 32850.0 & 39330.0 & 479.8 & 236.8 & 32350.0 & 6286.0 & 1355.0 & 208.3 \\
\hline & $\mathbf{F}$ & 110.6 & 49.6 & 6.3 & & 241.7 & 265.2 & 0.9 & & 138.7 & 166.1 & 2.0 & & 155.3 & 30.2 & 6.5 & \\
\hline & $\mathrm{p}$ value & $* * *$ & $* * *$ & $* *$ & & $* * *$ & $* * *$ & $\mathrm{~ns}$ & & $* * *$ & $* * *$ & ns & & $* * *$ & $* * *$ & $* *$ & \\
\hline & $\begin{array}{l}\% \text { of total } \\
\text { variation }\end{array}$ & 27.9 & 25.0 & 3.2 & & 25.5 & 56.0 & 0.2 & & 21.4 & 51.2 & 0.6 & & 38.6 & 15.0 & 3.2 & \\
\hline \multirow{7}{*}{${ }^{\text {sProline }}$} & $\begin{array}{l}\text { Sum of } \\
\text { squares }\end{array}$ & 8.4 & 713.8 & 149.8 & 388.8 & 83.6 & 519.8 & 28.2 & 601.4 & 187.2 & 338.3 & 7.0 & 166.3 & 25.1 & 309.0 & 64.2 & 279.7 \\
\hline & $\mathrm{df}$ & 1 & 2 & 2 & 174 & 1 & 2 & 2 & 174 & 1 & 2 & 2 & 174 & 1 & 2 & 2 & 174 \\
\hline & Mean square & 8.4 & 356.9 & 74.9 & 2.2 & 83.6 & 259.9 & 14.1 & 3.5 & 187.2 & 169.1 & 3.5 & 1.0 & 25.1 & 154.5 & 32.1 & 1.6 \\
\hline & & & & & & & & & & & & & & & & & \\
\hline & F & 3.7 & 159.7 & 33.5 & & 24.2 & 75.2 & 4.1 & & 195.8 & 177.0 & 3.6 & & 15.6 & 96.1 & 20.0 & \\
\hline & $\mathrm{p}$ value & ns & $* * *$ & $* * *$ & & $* * *$ & $* * *$ & * & & $* * *$ & $* * *$ & * & & $* * *$ & $* * *$ & $* * *$ & \\
\hline & $\begin{array}{l}\% \text { of total } \\
\text { variation }\end{array}$ & 0.7 & 56.6 & 11.9 & & 6.8 & 42.2 & 2.3 & & 26.8 & 48.4 & 1.0 & & 3.7 & 45.6 & 9.5 & \\
\hline
\end{tabular}

${ }^{*} \mathrm{p}<0.05 ;{ }^{* *} \mathrm{p}<0.01 ;{ }^{* *} \mathrm{p}<0.001$ by two-way ANOVA; $\mathrm{ns}=$ non-significant; $\mathrm{n}=30 ;{ }^{*}$, Normalized with their respective dry mass; $\$$, Normalized with their respective body weight. 
(a)

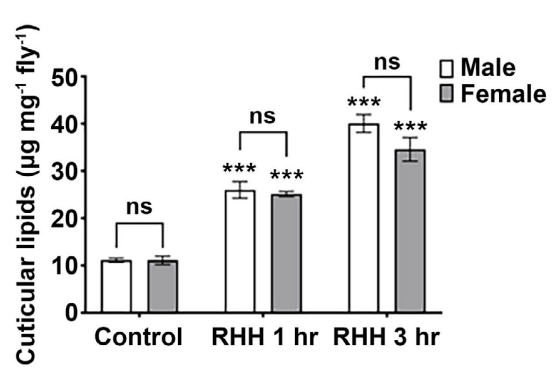

(b)

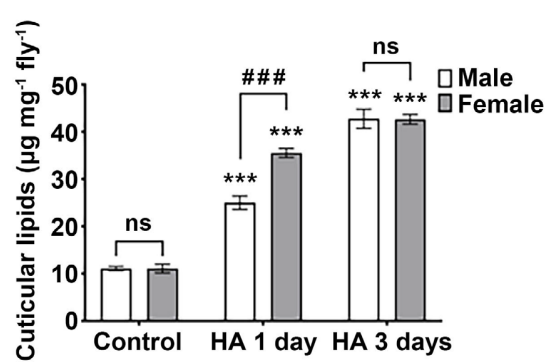

(c)

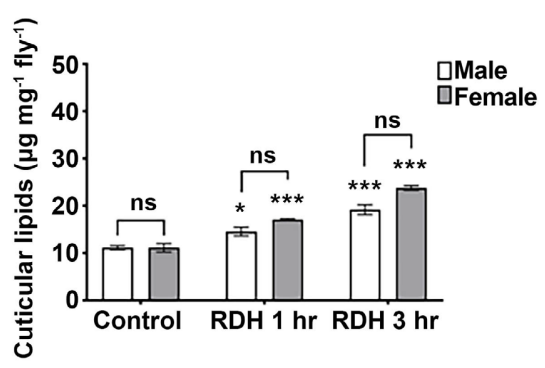

(d)

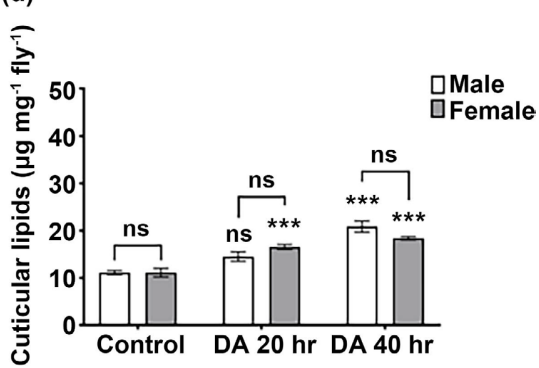

Figure 1. Changes in the levels of cuticular lipids $(\mathrm{CL})$ in response to (a) rapid heat hardening (RHH), (b) heat acclimation (HA), (c) rapid desiccation hardening (RDH), and (d) desiccation acclimation (DA). Statistical differences for RHH, HA, RDH and DA were tested with two-way ANOVA followed by Bonferroni test in male and female flies with their respective control $\left({ }^{*} \mathrm{p}<0.05 ;{ }^{*} \mathrm{p}<0.01 ;{ }^{* *} \mathrm{p}<0.001\right.$; ns $=$ non-significant $)$; between their respective male and female treated groups $\left({ }^{\#} \mathrm{p}<0.05 ;{ }^{\# \#} \mathrm{p}<0.01 ;{ }^{\# \# \#} \mathrm{p}<0.001\right)$. Values are represented as mean \pm S.E.M. of $(n=30)$ flies.

Similarly, during $1 \mathrm{hr} \mathrm{RDH}$, there was accumulation of CL in both males (30.57\% increase, $\mathrm{p}<0.05)$ and females (53.92\% increase, $\mathrm{p}<0.001)$. Additionally, during $3 \mathrm{hr}$ RHH the accumulation of CL increased further more significantly $(\mathrm{p}<0.001)$ in both males $(72.21 \%)$ and in females $(113.98 \%)$ of $Z$. indianus flies. Interestingly, the accumulation of CL under $20 \mathrm{hr}$ DA in males was non-significant whereas the accumulation of CL was significant $(p<0.001)$ in females $(49.14 \%)$. During $40 \mathrm{hr} \mathrm{DA}$, there was a significant $(\mathrm{p}<0.001)$ increase in the levels of CL in both the males $(87.32 \%)$ and in females (65.73\% increase) of $Z$. indianus.

\subsection{Differences in Accumulation and/or Utilization of Carbohydrates under Heat and Desiccation Stress}

The changes in the level of carbohydrates in $Z$. indianus flies reared under simulated season-specific conditions when subjected to different duration of heat and desiccation hardening and acclimation are shown in Figure 2 and Table 2. For heat stress, flies showing changes in the level of carbohydrates during heat hardening and acclimation are shown in Figure 2(a) \& Figure 2(b) respectively. Similarly for desiccation stress, flies showing changes in the level of carbohydrates during desiccation hardening and acclimation are shown in Figure 2(c) \& Figure 2(d) respectively. 
(a)

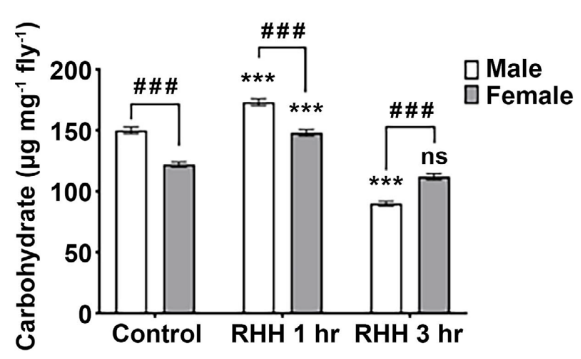

(b)

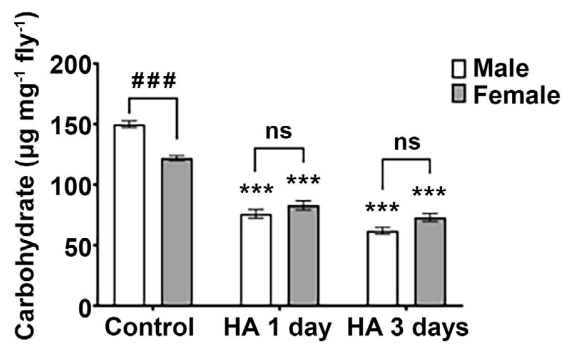

(c)

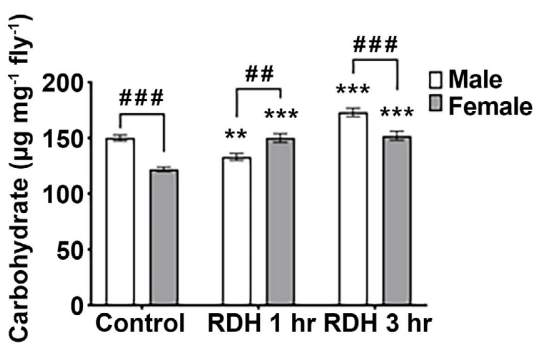

(d)

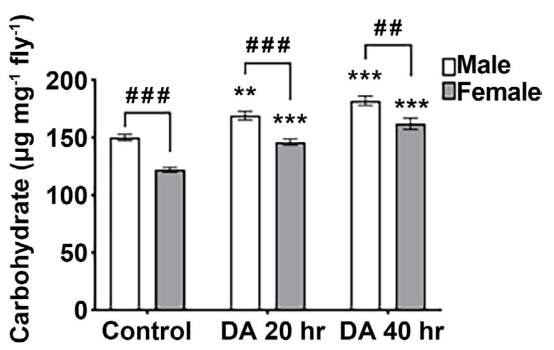

Figure 2. Changes in the levels of the carbohydrate content in response to (a) rapid heat hardening (RHH), (b) heat acclimation (HA), (c) rapid desiccation hardening (RDH), and (d) desiccation acclimation (DA). Statistical differences for RHH, HA, RDH and DA were tested with two-way ANOVA followed by Bonferroni test in male and female flies with their respective control $\left({ }^{*} \mathrm{p}<0.05 ;{ }^{* *} \mathrm{p}<0.01 ;{ }^{* *} \mathrm{p}<0.001 ; \mathrm{ns}=\right.$ non-significant $)$; between their respective male and female treated groups $\left({ }^{\#} \mathrm{p}<0.05 ;{ }^{\# \#} \mathrm{p}<0.01\right.$; ${ }^{\# \# \#} \mathrm{p}<$ $0.001)$. Values are represented as mean \pm S.E.M. of $(n=30)$ flies.

$1 \mathrm{hr}$ of RHH showed a significant $(\mathrm{p}<0.001)$ increase in the levels of carbohydrates in both the males (15.33\%) and females $(21.31 \%)$ of $Z$. indianus as compared to their respective controls. But during $3 \mathrm{hr}$ of $\mathrm{RHH}$, a significant ( $\mathrm{p}<$ $0.001)$ decrease in the carbohydrate level was observed in males $(40.00 \%)$ whereas no significant changes in females were observed in comparison to their respective controls. Furthermore, the carbohydrate content declined significantly ( $\mathrm{p}<0.001)$ after 1 day or 3 days of HA. In 1day HA, the levels of carbohydrate decreased by $49.33 \%$ in males and by $31.96 \%$ in females. Similarly, during 3 days HA the carbohydrate content decreased by $58.66 \%$ in males and by $40.16 \%$ in females of $Z$. indianus as compared to their respective controls.

The flies, when subjected to $1 \mathrm{hr} \mathrm{RDH}$, showed a significant $(\mathrm{p}<0.01)$ decrease in the levels of the carbohydrate content in males $(11.33 \%)$ in contrast to a significant $(\mathrm{p}<0.001)$ increase in females $(22.95 \%)$ as compared to their respective controls. However, during $3 \mathrm{hr} \mathrm{RDH}$ the levels of carbohydrates increased significantly ( $\mathrm{p}<0.001)$ in both the males $(15.33 \%)$ and in female $(24.59 \%)$ flies of Z. indianus.

Similar accumulation of carbohydrate content in $Z$. indianus flies were observed during DA. In $20 \mathrm{hr}$ DA, the accumulation of carbohydrate content in males by $12.66 \%$ and in females by $19.67 \%$ was significant $(p<0.01 \& p<0.001$ 
respectively). Further, during $40 \mathrm{hr}$ of DA the levels of carbohydrate content increased significantly $(\mathrm{p}<0.001)$ in both the males $(21.33 \%)$ and in females (32.78\% increase) of $Z$. indianus as compared to their respective controls. In general, flies showed a significant accumulation of carbohydrate content when subjected to RDH and DA.

\subsection{Differences in Accumulation and/or Utilization of Protein under Heat and Desiccation Stress}

The patterns of accumulation and utilization of protein in Zaprionus indianus under heat and desiccation stress are shown in Figure 3 and Table 2. For heat stress, flies showing changes in the level of protein during heat hardening and acclimation are shown in Figure 3(a) \& Figure 3(b) respectively. Similarly for desiccation stress, flies showing changes in the level of protein during desiccation hardening and acclimation are shown in Figure 3(c) \& Figure 3(d) respectively.

A significant $(\mathrm{p}<0.001)$ utilization of protein was observed under both $1 \mathrm{hr}$ and $3 \mathrm{hr}$ RHH. In $1 \mathrm{hr}$ RHH the level of total body proteins decreased by $33.24 \%$ in males and by $32.99 \%$ in females. Similarly, the level of proteins decreased by $26.48 \%$ in males and by $45.06 \%$ in females of $Z$. indianus under $3 \mathrm{hr}$ RHH when compared to their respective controls.

(a)

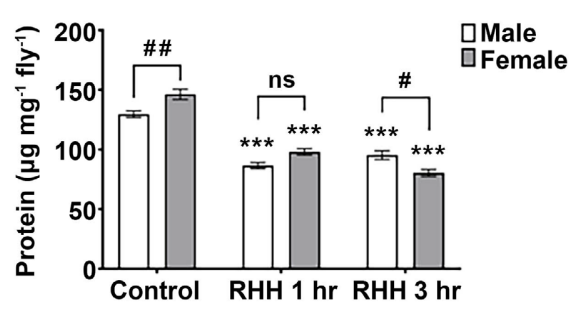

(c)

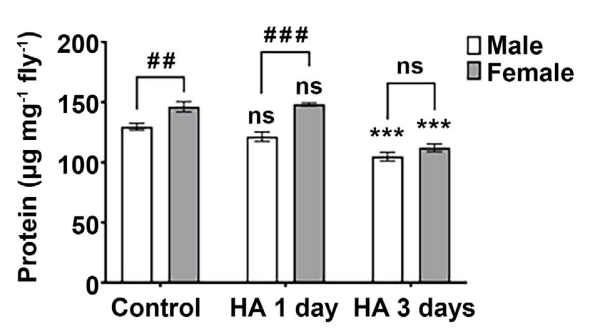

(c)

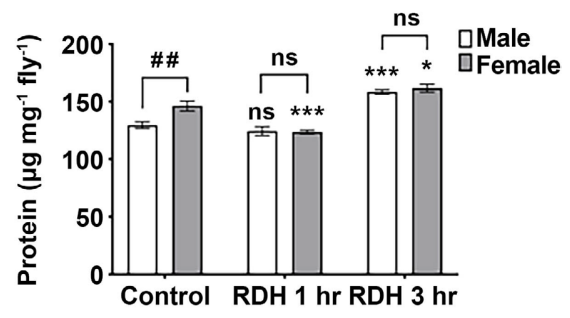

(d)

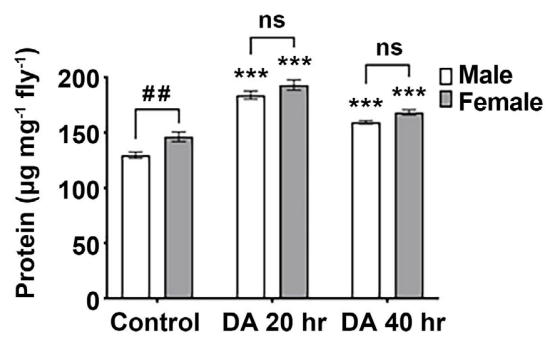

Figure 3. Changes in the levels of the protein content in response to (a) rapid heat hardening (RHH), (b) heat acclimation (HA), (c) rapid desiccation hardening (RDH), and (d) desiccation acclimation (DA). Statistical differences for RHH, HA, RDH and DA were tested with two-way ANOVA followed by Bonferroni test in male and female flies with their respective control $\left({ }^{*} \mathrm{p}<0.05 ;{ }^{* *} \mathrm{p}<0.01 ;{ }^{* *} \mathrm{p}<0.001\right.$; ns $=$ non-significant); between their respective male and female treated groups $\left({ }^{\#} \mathrm{p}<0.05 ;{ }^{\# \#} \mathrm{p}<0.01 ;{ }^{\# \#} \mathrm{p}<0.001\right)$. Values are represented as mean \pm S.E.M. of $(n=30)$ flies. 
When the flies were subjected to 1 day HA, there were non-significant changes in the levels of protein in both the males and females of $Z$. indianus flies. However, there was a significant $(\mathrm{p}<0.001)$ decrease in the levels of protein in both the males $(19.11 \%)$ and in females $(23.40 \%)$ of $Z$. indianus flies when subjected to $40 \mathrm{hr}$ HA stress.

In the case of $1 \mathrm{hr} \mathrm{RDH}$, the changes in the levels of protein in males were non-significant whereas we observed a significant $(\mathrm{p}<0.001)$ decrease in the level of protein in females $(15.46 \%)$ as compared to their respective controls. Interestingly, when the flies were subjected to $3 \mathrm{hr} \mathrm{RDH}$ we observed accumulation in the levels of protein. When subjected to $3 \mathrm{hr} \mathrm{RDH}$, the accumulation of protein in males by $22.25 \%$ was more significant $(\mathrm{p}<0.001)$ than in females $(10.57 \% ; \mathrm{p}<0.05)$ in comparison to their respective controls. Whereas, when it is subjected to DA stress, we observed a highly significant $(\mathrm{p}<0.001)$ accumulation of protein in $Z$. indianus flies. In $20 \mathrm{hr}$ DA, the level of protein in males increased by $41.88 \%$ and by $31.95 \%$ in females. Similarly, under $40 \mathrm{hr}$ DA the level of protein in males increased by $22.96 \%$ and in females by $15.08 \%$ in comparison to their respective controls.

\subsection{Variation in Accumulation and/or Utilization of Total Body Lipids (TBL) under Heat and Desiccation Stress}

Accumulation and utilization patterns of TBL under desiccation or heat stress are shown in Figure 4 and Table 2. For heat stress, flies showing changes in the level of TBL during heat hardening and acclimation are shown in Figure 4(a) \& Figure 4(b) respectively. Similarly for desiccation stress, flies showing changes in the level of TBL during desiccation hardening and acclimation are shown in Figure 4(c) \& Figure 4(d) respectively.

When the flies were subjected to $1 \mathrm{hr} \mathrm{RHH}$, there were non-significant changes in the level of TBL in both the males and in the females of $Z$. indianus flies. However, during $3 \mathrm{hr} \mathrm{RHH}$ the level of TBL increased significantly ( $\mathrm{p}<$ 0.001 ) in males $(29.97 \%)$ as well as in females $(10.61 \%)$ when compared to their respective controls. Interestingly a significant $(\mathrm{p}<0.001)$ decrease in the level of TBL was observed during HA stress with an effect on the exposure period. Under 1 day HA, the level of TBL decreased by $19.72 \%$ in males and by $15.67 \%$ in females. Similarly, under 3 days HA the level of TBL further decreased by $59.98 \%$ in males and by $41.71 \%$ in females of $Z$. indianus flies as compared to their respective controls.

During $1 \mathrm{hr} \mathrm{RDH}$, there were non-significant changes in the TBL levels in both the males and in females of $Z$. indianus flies. However, we observed a significant $(\mathrm{p}<0.001)$ utilization of TBL under $3 \mathrm{hr} \mathrm{RDH}$ in both the males (40.43\%) and females (38.58\%) of $Z$. indianus flies as compared to their respective controls. A similar trend of utilization of TBL was observed during DA stress too. There were non-significant changes during $20 \mathrm{hr}$ DA in both the males and in females of $Z$. indianus flies. In contrast, a significant $(\mathrm{p}<0.001)$ decrease in the level of TBL during $40 \mathrm{hr}$ DA in males (18.01\%) as well as in females 
(a)

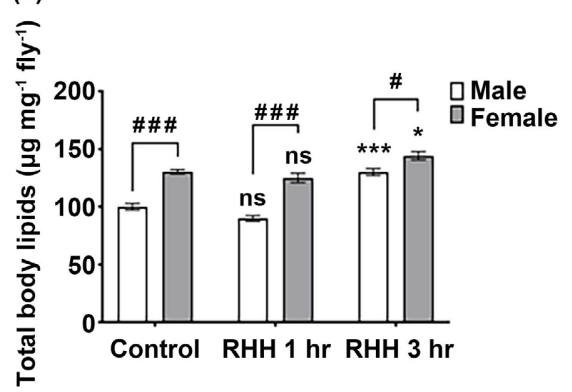

(b)

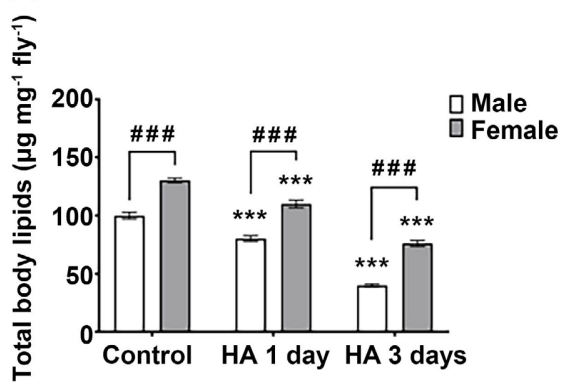

(c)

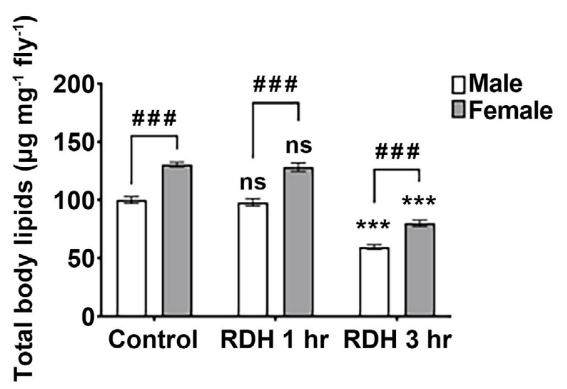

(d)

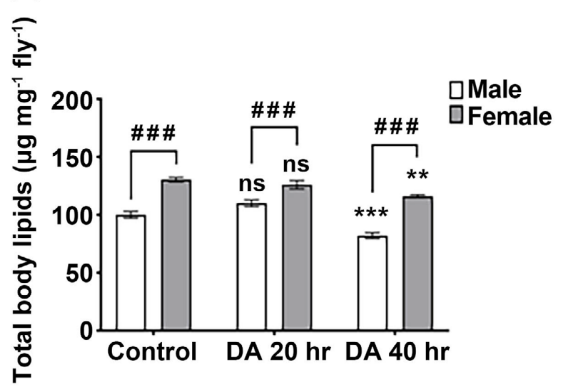

Figure 4. Changes in the levels of total body lipids (TBL) in response to (a) rapid heat hardening (RHH), (b) heat acclimation (HA), (c) rapid desiccation hardening (RDH), and (d) desiccation acclimation (DA). Statistical differences for RHH, HA, RDH and DA were tested with two-way ANOVA followed by Bonferroni test in male and female flies with their respective control $\left({ }^{*} \mathrm{p}<0.05 ;{ }^{* *} \mathrm{p}<0.01 ;{ }^{* *} \mathrm{p}<0.001 ; \mathrm{ns}=\right.$ non-significant $)$; between their respective male and female treated groups $\left({ }^{\#} \mathrm{p}<0.05 ;{ }^{\# \#} \mathrm{p}<0.01\right.$; ${ }^{\# \#} \mathrm{p}<$ $0.001)$. Values are represented as mean \pm S.E.M. of $(n=30)$ flies.

$(11.00 \% ; \mathrm{p}<0.01)$ were observed. These results suggest that the long-term exposure to stress (either heat or desiccation acclimation) leads to the mobilization or utilization of TBL in $Z$. indianus flies.

\subsection{Variation in Accumulation and/or Utilization of Proline under Heat and Desiccation Stress}

The patterns of proline accumulation and utilization in $Z$. indianus under heat and desiccation stress are shown in Figure 5 and Table 2. For heat stress, flies showing changes in the level of proline during heat hardening and acclimation are shown in Figure 5(a) \& Figure 5(b) respectively. Similarly for desiccation stress, flies showing changes in the level of proline during desiccation hardening and acclimation are shown in Figure 5(c) \& Figure 5(d) respectively.

A significant $(\mathrm{p}<0.001)$ increase in the level of proline was observed only during $\mathrm{RHH}$ stress. Under $1 \mathrm{hr} \mathrm{RHH}$ the level of proline in males increased by $75.62 \%$ and in females by $17.24 \%$. Similarly, under $3 \mathrm{hr}$ RHH the level of proline in males increased by $75.00 \%$ and in females by $29.04 \%$ when compared to their respective controls. During 1 day HA, the changes in the level of proline was non-significant in males but a significant $(\mathrm{p}<0.01)$ decrease in the level of proline were observed in females $(18.73 \%)$. Further when the flies were subjected to 
(a)

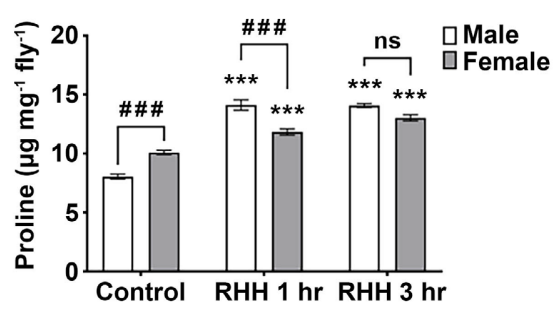

(b)

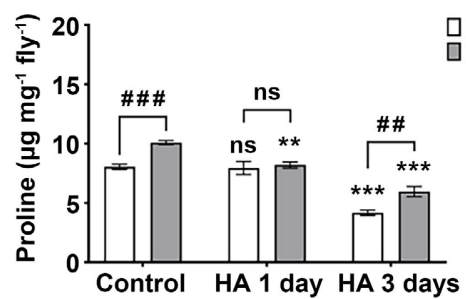

(c)

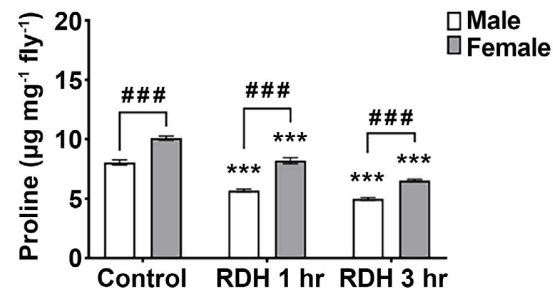

(d)

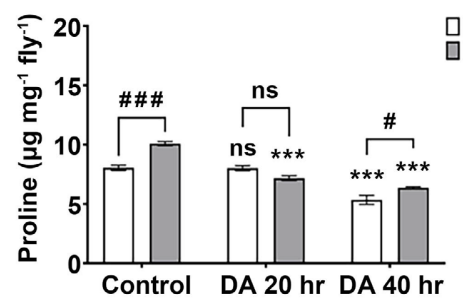

Figure 5. Changes in the levels of proline content in response to (a) rapid heat hardening $(\mathrm{RHH})$, (b) heat acclimation (HA), (c) rapid desiccation hardening (RDH), and (d) desiccation acclimation (DA). Statistical differences for RHH, HA, RDH and DA were tested with two-way ANOVA followed by Bonferroni test in male and female flies with their respective control $\left({ }^{*} \mathrm{p}<0.05 ;{ }^{* *} \mathrm{p}<0.01\right.$; ${ }^{* *} \mathrm{p}<0.001$; $\mathrm{ns}=$ non-significant); between their respective male and female treated groups $\left({ }^{\#} \mathrm{p}<0.05 ;{ }^{\# \#} \mathrm{p}<0.01\right.$; $\left.{ }^{\# \#} \mathrm{p}<0.001\right)$. Values are represented as mean \pm S.E.M. of $(n=30)$ flies.

3 days HA, a significant $(\mathrm{p}<0.001)$ decrease in the level of proline were observed in both the males $(48.13 \%)$ and females $(40.93 \%)$ of $Z$. indianus flies as compared to their respective controls.

A significant $(\mathrm{p}<0.001)$ decrease in the level of proline was observed during $\mathrm{RDH}$ ( $1 \mathrm{hr} \& 3 \mathrm{hr}$ ) stress. In $1 \mathrm{hr} \mathrm{RDH}$ the level of proline in males decreased by $29.35 \%$ and in females by $18.73 \%$. Similarly, during $3 \mathrm{hr} \mathrm{RDH}$ the level of proline decreased by $38.18 \%$ in males and by $35.38 \%$ in females of $Z$. indianus flies. When the flies were further subjected to $20 \mathrm{hr}$ DA, the changes in the level of proline were non-significant in males in contrast to a significant $(\mathrm{p}<0.001)$ decrease in female (28.84\%) flies. Under $40 \mathrm{hr}$ DA, we observed a significant ( $\mathrm{p}<$ $0.001)$ decrease in the level of proline in both the males (33.58\%) and in females (36.87\%) of $Z$. indianus flies in comparison to their respective controls. Hence the decrease in the level of proline suggests its utilization under desiccation stress.

Finally, the results of the Bonferroni test for adult hardening/acclimation to heat or desiccation stress on various metabolites in $Z$. indianus flies are shown in Table 3.

\section{Discussion}

Environmental stress such as ambient temperature and humidity has significant effects on the physiology of the organisms. The adaptability and tolerance to 
Table 3. Results of Bonferroni test for adult hardening/acclimation to heat or desiccation stress on various metabolites in male and female $Z$. indianus.

\begin{tabular}{|c|c|c|c|c|c|c|c|c|c|c|c|}
\hline \multirow{2}{*}{$\begin{array}{l}\text { Treatment } \\
\text { Group (I) }\end{array}$} & \multirow{2}{*}{$\begin{array}{l}\text { Treatment } \\
\text { Group (J) }\end{array}$} & \multicolumn{2}{|c|}{ Cuticular Lipids } & \multicolumn{2}{|c|}{ Carbohydrates } & \multicolumn{2}{|c|}{ Total Body Protien } & \multicolumn{2}{|c|}{ Total Body Lipids } & \multicolumn{2}{|c|}{ Proline } \\
\hline & & I-J & Sig. & I-J & Sig. & I-J & Sig. & I-J & Sig. & I-J & Sig. \\
\hline \multicolumn{12}{|c|}{ Rapid Heat Hardening ( $\mathrm{RHH})$} \\
\hline Control:Male & Control:Female & 0.02 & ns & 28.00 & $* * *$ & -16.66 & $* *$ & -30.37 & $* * *$ & -2.05 & $* * *$ \\
\hline Control:Male & RHH 1 hr:Male & -14.88 & $* * *$ & -23.00 & $* * *$ & 43.09 & $* * *$ & 10.09 & ns & -6.08 & $* * *$ \\
\hline Control:Male & RHH 1 hr:Female & -13.98 & $* * *$ & 2.00 & ns & 31.57 & $* * *$ & -24.95 & $* * *$ & -3.78 & $* * *$ \\
\hline Control:Male & RHH 3 hr:Male & -28.92 & $* * *$ & 60.00 & $* * *$ & 34.34 & $* * *$ & -29.99 & $* * *$ & -6.03 & $* * *$ \\
\hline Control:Male & RHH 3 hr:Female & -23.46 & $* * *$ & 38.00 & $* * *$ & 49.27 & $* * *$ & -44.19 & $* * *$ & -4.98 & $* * *$ \\
\hline Control:Female & RHH 1 hr:Male & -14.90 & $* * *$ & -51.00 & $* * *$ & 59.75 & $* * *$ & 40.46 & $* * *$ & -4.03 & $* * *$ \\
\hline Control:Female & RHH 1 hr:Female & -14.00 & $* * *$ & -26.00 & $* * *$ & 48.24 & $* * *$ & 5.43 & ns & -1.74 & $* * *$ \\
\hline Control:Female & RHH 3 hr:Male & -28.94 & $* * *$ & 32.00 & $* * *$ & 51.00 & $* * *$ & 0.38 & ns & -3.98 & $* * *$ \\
\hline Control:Female & RHH 3 hr:Female & -23.49 & $* * *$ & 10.00 & ns & 65.93 & $* * *$ & -13.82 & * & -2.94 & $* * *$ \\
\hline RHH 1 hr:Male & RHH 1 hr:Female & 0.90 & ns & 25.00 & $* * *$ & -11.52 & ns & -35.04 & $* * *$ & 2.29 & $* * *$ \\
\hline RHH 1 hr:Male & RHH 3 hr:Male & -14.04 & $* * *$ & 83.00 & $* * *$ & -8.75 & ns & -40.08 & $* * *$ & 0.05 & ns \\
\hline RHH 1 hr:Male & RHH 3 hr:Female & -8.59 & $* *$ & 61.00 & $* * *$ & 6.18 & ns & -54.28 & $* * *$ & 1.09 & ns \\
\hline RHH 1 hr:Female & RHH 3 hr:Male & -14.94 & $* * *$ & 58.00 & $* * *$ & 2.76 & ns & -5.05 & ns & -2.25 & $* * *$ \\
\hline RHH 1 hr:Female & RHH 3 hr:Female & -9.49 & $* * *$ & 36.00 & $* * *$ & 17.69 & $* *$ & -19.24 & $* * *$ & -1.20 & * \\
\hline RHH 3 hr:Male & RHH 3 hr:Female & 5.46 & ns & -22.00 & $* * *$ & 14.93 & * & -14.20 & * & 1.05 & ns \\
\hline \multicolumn{12}{|c|}{ Heat Acclimation (HA) } \\
\hline Control:Male & HA 1 day:Male & -13.89 & $* * *$ & 74.00 & $* * *$ & 8.24 & ns & 19.73 & $* * *$ & 0.09 & ns \\
\hline Control:Male & HA 1 day:Female & -24.40 & $* * *$ & 67.00 & $* * *$ & -18.55 & ** & -9.91 & ns & -0.16 & ns \\
\hline Control:Male & HA 3 days:Male & -31.63 & $* * *$ & 88.00 & $* * *$ & 24.78 & $* * *$ & 60.01 & $* * *$ & 3.87 & $* * *$ \\
\hline Control:Male & HA 3 days:Female & -31.49 & $* * *$ & 77.00 & $* * *$ & 17.59 & $* *$ & 24.04 & $* * *$ & 2.08 & $* * *$ \\
\hline Control:Female & HA 1 day:Male & -13.91 & $* * *$ & 46.00 & $* * *$ & 24.90 & $* * *$ & 50.10 & $* * *$ & 2.14 & $* * *$ \\
\hline Control:Female & HA 1 day:Female & -24.42 & $* * *$ & 39.00 & $* * *$ & -1.89 & ns & 20.46 & $* * *$ & 1.89 & ** \\
\hline Control:Female & HA 3 days:Male & -31.65 & $* * *$ & 60.00 & $* * *$ & 41.44 & $* * *$ & 90.38 & $* * *$ & 5.91 & $* * *$ \\
\hline Control:Female & HA 3 days:Female & -31.51 & $* * *$ & 49.00 & $* * *$ & 34.25 & $* * *$ & 54.41 & $* * *$ & 4.13 & $* * *$ \\
\hline HA 1 day:Male & HA 1 day:Female & -10.51 & $* * *$ & -7.00 & ns & -26.79 & $* * *$ & -29.64 & $* * *$ & -0.25 & ns \\
\hline HA 1 day:Male & HA 3 days:Male & -17.74 & $* * *$ & 14.00 & * & 16.54 & $* *$ & 40.28 & $* * *$ & 3.78 & $* * *$ \\
\hline HA 1 day:Male & HA 3 days:Female & -17.60 & $* * *$ & 3.00 & ns & 9.35 & ns & 4.31 & ns & 1.99 & $* * *$ \\
\hline HA 1 day:Female & HA 3 days:Male & -7.23 & $* * *$ & 21.00 & $* * *$ & 43.33 & $* * *$ & 69.92 & $* * *$ & 4.03 & $* * *$ \\
\hline HA 1 day:Female & HA 3 days:Female & -7.09 & $* * *$ & 10.00 & ns & 36.14 & $* * *$ & 33.95 & $* * *$ & 2.24 & $* * *$ \\
\hline HA 3 days:Male & HA 3 days:Female & 0.14 & $\mathrm{~ns}$ & -11.00 & ns & -7.20 & ns & -35.97 & $* * *$ & -1.79 & ** \\
\hline
\end{tabular}




\begin{tabular}{|c|c|c|c|c|c|c|c|c|c|c|c|}
\hline \multicolumn{12}{|c|}{ Rapid Desiccation Hardening (RDH) } \\
\hline Control:Male & RDH 1 hr:Male & -3.40 & * & 17.00 & ** & 5.21 & ns & 2.08 & ns & 2.36 & $* * * *$ \\
\hline Control:Male & RDH 1 hr:Female & -5.95 & $* * *$ & 0.00 & ns & 5.97 & ns & -28.11 & $* * *$ & -0.16 & ns \\
\hline Control:Male & RDH 3 hr:Male & -8.04 & $* * *$ & -23.00 & $* * *$ & -28.82 & $* * *$ & 40.45 & $* * *$ & 3.07 & $* * * *$ \\
\hline Control:Male & RDH 3 hr:Female & -12.62 & $* * *$ & -2.00 & ns & -32.11 & $* * *$ & 19.96 & $* * *$ & 1.52 & $* * * *$ \\
\hline Control:Female & RDH 1 hr:Male & -3.43 & * & -11.00 & ns & 21.88 & $* * *$ & 32.46 & $* * *$ & 4.40 & $* * * *$ \\
\hline Control:Female & RDH 1 hr:Female & -5.98 & $* * *$ & -28.00 & $* * *$ & 22.63 & $* * *$ & 2.26 & ns & 1.89 & $* * * *$ \\
\hline Control:Female & RDH 3 hr:Male & -8.06 & $* * *$ & -51.00 & $* * *$ & -12.16 & ns & 70.82 & $* * *$ & 5.12 & $* * * *$ \\
\hline Control:Female & RDH 3 hr:Female & -12.64 & $* * *$ & -30.00 & $* * *$ & -15.45 & * & 50.33 & $* * *$ & 3.56 & $* * * *$ \\
\hline RDH 1 hr:Male & RDH 1 hr:Female & -2.55 & ns & -17.00 & $* *$ & 0.75 & $\mathrm{~ns}$ & -30.19 & $* * *$ & -2.52 & $* * * *$ \\
\hline RDH 1 hr:Male & RDH 3 hr:Male & -4.64 & $* * *$ & -40.00 & $* * *$ & -34.04 & $* * *$ & 38.37 & $* * *$ & 0.71 & ns \\
\hline RDH 1 hr:Male & RDH 3 hr:Female & -9.21 & $* * *$ & -19.00 & $* *$ & -37.32 & $* * *$ & 17.88 & $* * *$ & -0.84 & * \\
\hline RDH 1 hr:Female & RDH 3 hr:Male & -2.08 & ns & -23.00 & $* * *$ & -34.79 & $* * *$ & 68.56 & $* * *$ & 3.23 & $* * * *$ \\
\hline RDH 1 hr:Female & RDH 3 hr:Female & -6.66 & $* * *$ & -2.00 & ns & -38.08 & $* * *$ & 48.07 & $* * *$ & 1.68 & $* * * *$ \\
\hline RDH 3 hr:Male & RDH 3 hr:Female & -4.58 & $* * *$ & 21.00 & $* * *$ & -3.29 & ns & -20.49 & $* * *$ & -1.55 & $* * * *$ \\
\hline \multicolumn{12}{|c|}{ Desiccation Acclimation (DA) } \\
\hline Control:Male & DA $20 \mathrm{hr}:$ Male & -3.37 & $\mathrm{~ns}$ & -19.00 & $* *$ & -54.28 & $* * *$ & -9.91 & ns & 0.02 & ns \\
\hline Control:Male & DA $20 \mathrm{hr}$ :Female & -5.42 & $* * *$ & 4.00 & ns & -63.41 & $* * *$ & -25.95 & $* * *$ & 0.86 & ns \\
\hline Control:Male & DA $40 \mathrm{hr}:$ Male & -9.72 & $* * *$ & -32.00 & $* * *$ & -29.79 & $* * *$ & 18.02 & $* * *$ & 2.70 & $* * *$ \\
\hline Control:Male & DA $40 \mathrm{hr}$ :Female & -7.26 & $* * *$ & -12.00 & ns & -38.71 & $* * *$ & -16.00 & $* * *$ & 1.67 & $* * *$ \\
\hline Control:Female & DA $20 \mathrm{hr}:$ Male & -3.39 & * & -47.00 & $* * *$ & -37.62 & $* * *$ & 20.46 & $* * *$ & 2.07 & $* * *$ \\
\hline Control:Female & DA $20 \mathrm{hr}$ :Female & -5.45 & $* * *$ & -24.00 & $* * *$ & -46.74 & $* * *$ & 4.42 & ns & 2.91 & $* * *$ \\
\hline Control:Female & DA $40 \mathrm{hr}:$ Male & -9.74 & $* * *$ & -60.00 & $* * *$ & -13.12 & ns & 48.39 & $* * *$ & 4.74 & $* * *$ \\
\hline Control:Female & DA 40 hr:Female & -7.28 & $* * *$ & -40.00 & $* * *$ & -22.05 & $* * *$ & 14.37 & $* *$ & 3.71 & $* * *$ \\
\hline DA $20 \mathrm{hr}:$ Male & DA $20 \mathrm{hr}$ :Female & -2.06 & ns & 23.00 & $* * *$ & -9.12 & $\mathrm{~ns}$ & -16.04 & $* * *$ & 0.84 & ns \\
\hline DA $20 \mathrm{hr}:$ Male & DA $40 \mathrm{hr}:$ Male & -6.35 & $* * *$ & -13.00 & ns & 24.50 & $* * *$ & 27.93 & $* * *$ & 2.67 & $* * *$ \\
\hline DA $20 \mathrm{hr}:$ Male & DA $40 \mathrm{hr}$ :Female & -3.89 & * & 7.00 & ns & 15.57 & * & -6.09 & ns & 1.64 & $* * *$ \\
\hline DA $20 \mathrm{hr}$ :Female & DA 40 hr:Male & -4.29 & $* *$ & -36.00 & $* * *$ & 33.62 & $* * *$ & 43.97 & $* * *$ & 1.84 & $* * *$ \\
\hline DA $20 \mathrm{hr}$ :Female & DA $40 \mathrm{hr}$ :Female & -1.84 & ns & -16.00 & * & 24.69 & $* * *$ & 9.95 & ns & 0.81 & ns \\
\hline DA $40 \mathrm{hr}:$ Male & DA 40 hr:Female & 2.46 & ns & 20.00 & $* *$ & -8.93 & ns & -34.02 & $* * *$ & -1.03 & * \\
\hline
\end{tabular}

$\left({ }^{*} \mathrm{p}<0.05 ;{ }^{* *} \mathrm{p}<0.01 ;{ }^{* * *} \mathrm{p}<0.001 ; \mathrm{ns}=\right.$ non-significant $)$.

these sudden changes in the environment is the key determinant of the species survival and abundance in a geographical location. It has been argued that climatic stressors can limit the survival of ectothermic organisms through perturbation in the energy budget [18] [29]. In tropical regions, hot and dry conditions occur together but their relative magnitudes differ across different seasons. The 
acclimatization of $Z$. indianus under seasonally varying environment conditions involves the simultaneous effects of both desiccation and heat stressors. For ectothermic organisms, this can lead to morphological and physiological changes to cope with hot and drier habitats. In small-sized organisms like Drosophila, energetic homeostasis could be a major problem under climatic stressors. In the present study on $Z$. indianus living in harsh environments, we try to elucidate the possible linkage between physiological changes and heat and desiccation stress. We assessed the effects of stressor, either heat or desiccation hardening or acclimation, for different duration on the levels of various metabolites. In addition, both the stressors can crosstalk between accumulation and utilization of energy metabolites which suggests a link between the two stressors for providing energetic homeostasis. Rapid hardening involves the stress given with high intensity for a short duration of time whereas for acclimation the stress is given for a longer duration with low intensity.

The storage of fatty acids and glucose is essential in insects for survival, and they are vital for many physiological functions. Fatty acids serve as precursors in the synthesis of eicosanoids and pheromones, and they are needed in substantial amounts for the synthesis of phospholipids and waxes [19]. This may be the reason for the utilization of carbohydrates during heat acclimation with the corresponding increase of cuticular lipids for their survival for a longer time as well as to reduce the water loss due to heat. Whereas an increase in carbohydrates during rapid heat hardening ( $\mathrm{RHH} 1 \mathrm{hr}$ ) corresponds to available energy for immediate requirement since carbohydrate is known to increase the fat content of the flies [30].

In the tropical drosophilid-Zaprionus indianus, $\mathrm{G}_{1-2}$ laboratory flies reared under season-specific simulated conditions showed significant differences in metric traits (wet weight and dry weight) between male and female flies (Table 1 ). In the current study performed in male and female $Z$. indianus, we found that the HA both for 1 day and 3 days decrease total body lipid. In a recent study performed in Drosophila, a similar decrease in total body lipid was also observed [31]. It is interesting to note that heat stress, even for a short duration, can leave a long-lasting effect on total body lipid [31]. The decrease in body lipid was mainly due to heat stress-induced increased apoptosis in fat bodies and therefore flies were unable to recover the body lipid even after several days due to irreversible changes in body lipid reserve. Another possible explanation for the decrease in body lipid during HA might be due to a deficit in energy intake as compared to energy expenditure. Heat stress is known to increase metabolic rate and therefore promote energy expenditure. Similarly, in arthropods, the increased temperature has been shown to reduce the energy intake more rapidly than energy expenditure [32]. Moreover, long-term exposure to high temperatures is an energetically costly process and requires the transcription of several heat shock proteins and proteins involved in the repair of cell damage which costs a substantial amount of energy. Although both body lipid and carbohydrates have been key sources providing energy during thermal and environmen- 
tal stress. Other carbohydrates like glycogen and trehalose are especially required for more vital physiological functions required for survival, flight, and also as anoxia resistance [33]. Similar studies have also shown an increase in trehalose during both desiccation acclimation and heat hardening but there was no change in the level of trehalose due to starvation acclimation [34]. The combined effect of both desiccation and heat showed a maximum increase in the level of trehalose. Interestingly combined effect of starvation with either heat or desiccation also increased the level of trehalose. They have further stated that the accumulation of trehalose during heat hardening might be for protecting the flies from the detrimental effects of heat stress.

In the present study, both $3 \mathrm{~h} \mathrm{RHH}$ and HA have been shown to reduce carbohydrate level, however, $1 \mathrm{~h} \mathrm{RHH}$ treatment increased carbohydrate level. In contrast to $\mathrm{HA}$ and $\mathrm{RHH}$, we observed an increase in the level of carbohydrates and protein due to desiccation acclimation. Periods of starvation/desiccation are encountered by most animals, but they can adjust their metabolism by mobilizing stored energy for survival. However, needs differ considerably between species and so their adaptations to starvation/desiccation stress might also differ. Insects possess a high surface-to-volume ratio of lipids and this, combined with an open blood system, renders them susceptible to desiccation.

Both HA and RHH led to a decrease in protein level and this may be due to heat stress-induced increase in denatured protein and subsequent breakdown. It is well established that heat shock proteins are induced over a given temperature [35]. Conversely, heat stress is also followed by a massive synthesis of heat shock proteins to counteract the adverse effect of heat stress on protein stability. The carbohydrate and trehalose protect membrane integrity and protein during heat stress. The previous study in Drosophila melanogaster larva has shown that the external feeding of proteins and carbohydrates affects its thermal and desiccation stress [36].

In addition, trehalose and proline contribute as non-toxic osmolytes during heat stress to provide osmotic protection and protect proteins and membranes from denaturation [37] [38]. Proline is a major energy source both in plants and insects which theoretically provides around 14 ATP molecules during its partial oxidation to alanine [39]. The role of proline under various climatic stresses has been discussed previously in both plants [40] and drosophilids [17] [34]. In a mammalian cell, an increase in intracellular and extracellular proline protects cells from oxidative stress [41]. In hymenopterans, dipterans, coleopterans, and several other insects, proline has been found to act as an energy source by providing intermediate substrates for the Krebs cycle and promoting the oxidation of carbohydrates [42] [43] [44] [45] [46]. More importantly, it can act as a shuttle to mobilize lipid reserves in the fat bodies [19] [42] [47]. The accumulation of proline during RHH corresponds to a previous study where there was an accumulation of proline due to heat stress [34].

In the present work, the utilization of proline in $Z$. indianus under $\mathrm{HA}, \mathrm{RDH}$ and DA is an interesting observation. This utilization of proline may have oc- 
curred for the possible requirement of energy source against different stressors. In the current study during $\mathrm{RHH}$ we observed an increase in proline however decreases during HA. This suggests the role of proline in providing osmotic protection and protects membranes from damage during sudden exposure to heat stress. It is likely that during the HA process, the activation of other stress related genes and heat shock proteins might be taking over this function of proline and therefore making it redundant. Our result matches the previous studies in dog tick where there was a decrease in the level of metabolites such as proteins and lipids during desiccation stress [7]. Previous reports have also shown the utilization of proline but only during insect flight [48] [49].

Fats upon oxidation, yield two times more metabolic water than carbohydrates or protein, and the storage of energy reserves in the form of fat provides a useful source of non-imbibed water. This additional water assumes particular importance during non-feeding stages in the insect's life history [50]. It may be due to such reasons that there was a decrease in the level of total body lipids during long-term exposure of heat acclimation and also during desiccation hardening and acclimation. Further, the molecular configuration of certain cuticular lipids constitutes the major barrier to water loss and may facilitate absorption of atmospheric water [19] [50]. Hence, it may be due to this reason that there was a high accumulation of cuticular lipids during heat stress but a gradual increase in CL during desiccation stress. Overall, during both the stresses, the level of CL increases to act as a water barrier. Increasing temperature is associated with an elevated level of certain kinds of lipids [51]. This helps in the adaptation of species under high-temperature stress. For dehydration tolerance, metabolic depression is a common adaptation. It has been observed in the larva of $B$. antartica that they conserve energy during prolonged dehydration by down-regulating genes related to metabolism [6]. This may minimize respiratory as well as loss of water bound to glycogen and other carbohydrates. Animals are more susceptible to water loss during high-temperature stress than dehydration stress. Hence, it may be due to this reason that there was a very high accumulation of cuticular lipids during heat stress but a gradual increase in CL during desiccation stress.

We have assessed changes only in a few energy metabolites while other metabolites are expected to show minor or major alterations. However, the higher concentrations of cuticular lipids, carbohydrates, and protein in insects can provide a good index for monitoring changes in these energy metabolites in wild populations of diverse Drosophila species [17]. It has been argued that stress-induced accumulation of energy metabolite is relevant if it is utilized in a temporal manner [18] [29]. Therefore, a comparison of the level of energy metabolites of $Z$.indianus subjected to heat or desiccation has supported the argument of possible compensation to achieve energetic homeostasis. Since $Z$. indianus is also considered as a pest to many fruit orchards, such studies will help us in better habitat management which may further be helpful for the biological control of such species without any human interference [52]. 


\section{Conclusion}

In summary, we found contrasting results for heat or desiccation stress-induced changes in energy metabolites (CL, TBL, proline, protein, and carbohydrates) in $Z$ indianus. Heat-induced changes include accumulation of CL but utilization of protein and carbohydrates. In contrast, desiccation-induced changes showed accumulation of protein and carbohydrate but utilization of TBL and proline. Carbohydrate is the immediate energy source being available during hardening and being utilized during acclimation with the increased cuticular lipid. Thus, there is a compensatory link between heat versus desiccation and hardening versus acclimation induced changes in the level of these metabolites which can provide energetic homeostasis in seasonal populations of $Z$. indianus. It may also help the species for better adaptation. Observed changes in the levels of accumulation and utilization of each energy metabolite suggest a link between the two stressors i.e. heat and desiccation tolerance with adaptation. Thus, $Z$. indianus has adopted a strategy of complementary changes in energy metabolite levels to maintain the energetic balance of these potential sources of energy for survival under hot and drier seasonal environmental conditions. Such mechanisms are likely to be present in other heat-adapted ectothermic organisms which need further investigations to find the generality of such seasonal physiological adaptations.

\section{Acknowledgements}

This study was supported by grants from DBT-BIOCARE and DST-SERB to PS. RKS is thankful to DBT284 Ramalingaswami fellowship

(BT/RLF/Re-entry/33/2017). AMT is thankful to National Fellowship for Higher Education of ST students for providing the research fellowship.

\section{Conflicts of Interest}

The authors declare no conflicts of interest regarding the publication of this paper.

\section{References}

[1] Girish, T.N., Pradeep, B.E. and Parkash, R. (2018) Heat- and Humidity-Induced Plastic Changes in Body Lipids and Starvation Resistance in the Tropical Fly Zaprionus indianus during Wet and Dry Seasons. Journal of Experimental Biology, 221, Article ID: 174482. https://doi.org/10.1242/jeb.174482

[2] Chown, S.L., Sørensen, J.G. and Terblanche, J.S. (2011) Water Loss in Insects: An Environmental Change Perspective. Journal of Insect Physiology, 57, 1070-1084. https://doi.org/10.1016/j.jinsphys.2011.05.004

[3] Williams, C.M., Watanabe, M., Guarracino, M.R., Ferraro, M.B., Edison, A.S., Morgan, T.J., et al. (2014) Cold Adaptation Shapes the Robustness of Metabolic Networks in Drosophila melanogaster. Evolution, 68, 3505-3523. https://doi.org/10.1111/evo.12541

[4] Benoit, J.B., Lopez-Martinez, G., Elnitsky, M.A., Lee, R.E. and Denlinger, D.L. (2009) Dehydration-Induced Cross Tolerance of Belgica antarctica Larvae to Cold and Heat Is Facilitated by Trehalose Accumulation. Comparative Biochemistry and 
Physiology Part A: Molecular \& Integrative Physiology, 152, 518-523.

https://doi.org/10.1016/j.cbpa.2008.12.009

[5] Teets, N.M., Kawarasaki, Y., Lee, R.E. and Denlinger, D.L. (2011) Survival and Energetic Costs of Repeated Cold Exposure in the Antarctic Midge, Belgica antarctica: A Comparison between Frozen and Supercooled Larvae. Journal of Experimental Biology, 214, 806-814. https://doi.org/10.1242/jeb.051912

[6] Teets, N.M., Kawarasaki, Y., Lee, R.E. and Denlinger, D.L. (2012) Energetic Consequences of Repeated and Prolonged Dehydration in the Antarctic Midge, Belgica antarctica. Journal of Insect Physiology, 58, 498-505.

https://doi.org/10.1016/j.jinsphys.2011.11.011

[7] Rosendale, A.J., Dunlevy, M.E., Fieler, A.M., Farrow, D.W., Davies, B. and Benoit, J.B. (2017) Dehydration and Starvation Yield Energetic Consequences That Affect Survival of the American Dog Tick. Journal of Insect Physiology, 101, 39-46. https://doi.org/10.1016/j.jinsphys.2017.06.012

[8] Chown, S.L., Chown, S. and Nicolson, S. (2004) Insect Physiological Ecology: Mechanisms and Patterns. Oxford University Press. https://doi.org/10.1093/acprof:oso/9780198515494.001.0001

[9] Harrison, J.F., Woods, H.A. and Roberts, S.P. (2012) Ecological and Environmental Physiology of Insects. Oxford University Press. https://doi.org/10.1093/acprof:oso/9780199225941.001.0001

[10] Hoffmann, A.A., Sørensen, J.G. and Loeschcke, V. (2003) Adaptation of Drosophila to Temperature Extremes: Bringing Together Quantitative and Molecular Approaches. Journal of Thermal Biology, 28, 175-216. https://doi.org/10.1016/S0306-4565(02)00057-8

[11] Angilletta, M.J. (2009) Thermal Adaptation: A Theoretical and Empirical Synthesis. Oxford University Press. https://doi.org/10.1093/acprof:oso/9780198570875.001.1

[12] Bale, J.S. and Hayward, S.A.L. (2010) Insect Overwintering in a Changing Climate. Journal of Experimental Biology, 213, 980-994. https://doi.org/10.1242/jeb.037911

[13] Schou, M.F., Loeschcke, V. and Kristensen, T.N. (2015) Strong Costs and Benefits of Winter Acclimatization in Drosophila melanogaster. PLoS ONE, 10, e0130307. https://doi.org/10.1371/journal.pone.0130307

[14] Rajamohan, A. and Sinclair, B.J. (2009) Hardening Trumps Acclimation in Improving Cold Tolerance of Drosophila melanogaster Larvae. Physiological Entomology, 34, 217-223. https://doi.org/10.1111/j.1365-3032.2009.00677.x

[15] Koštál, V., Korbelová, J., Rozsypal, J., Zahradníčková, H., Cimlová, J., Tomčala, A. and Šimek, P. (2011) Long-Term Cold Acclimation Extends Survival Time at $0^{\circ} \mathrm{C}$ and Modifies the Metabolomic Profiles of the Larvae of the Fruit Fly Drosophila melanogaster. PLoS ONE, 6, e25025. https://doi.org/10.1371/journal.pone.0025025

[16] Benoit, J.B., Lopez-Martinez, G., Michaud, M.R., Elnitsky, M.A., Lee, R.E. and Denlinger, D.L. (2007) Mechanisms to Reduce Dehydration Stress in Larvae of the Antarctic Midge, Belgica antarctica. Journal of Insect Physiology, 53, 656-667. https://doi.org/10.1016/j.jinsphys.2007.04.006

[17] Tamang, A.M., Kalra, B. and Parkash, R. (2017) Cold and Desiccation Stress Induced Changes in the Accumulation and Utilization of Proline and Trehalose in Seasonal Populations of Drosophila immigrans. Comparative Biochemistry and Physiology Part A: Molecular \& Integrative Physiology, 203, 304-313. https://doi.org/10.1016/j.cbpa.2016.10.011

[18] Marron, M.T., Markow, T.A., Kain, K.J. and Gibbs, A.G. (2003) Effects of Starvation and Desiccation on Energy Metabolism in Desert and Mesic Drosophila. Journal of 
Insect Physiology, 49, 261-270. https://doi.org/10.1016/S0022-1910(02)00287-1

[19] Arrese, E.L. and Soulages, J.L. (2010) Insect Fat Body: Energy, Metabolism, and Regulation. Annual Review of Entomology, 55, 207-225.

https://doi.org/10.1146/annurev-ento-112408-085356

[20] Goyal, K., Walton, L.J., Browne, J.A., Burnell, A.M. and Tunnacliffe, A. (2005) Molecular Anhydrobiology: Identifying Molecules Implicated in Invertebrate Anhydrobiosis. Integrative and Comparative Biology, 45, 702-709.

https://doi.org/10.1093/icb/45.5.702

[21] Michaud, M.R., Benoit, J.B., Lopez-Martinez, G., Elnitsky, M.A., Lee, R.E. and Denlinger, D.L. (2008) Metabolomics Reveals Unique and Shared Metabolic Changes in Response to Heat Shock, Freezing and Desiccation in the Antarctic Midge, Belgica antarctica. Journal of Insect Physiology, 54, 645-655.

https://doi.org/10.1016/j.jinsphys.2008.01.003

[22] Koštál, V., Zahradníčková, H. and Šimek, P. (2011) Hyperprolinemic Larvae of the Drosophilid Fly, Chymomyza costata, Survive Cryopreservation in Liquid Nitrogen. Proceedings of the National Academy of Sciences of the United States of America, 108, 13041-13046. https://doi.org/10.1073/pnas.1107060108

[23] Overgaard, J., Malmendal, A., Sørensen, J.G., Bundy, J.G., Loeschcke, V., Nielsen, N.C. and Holmstrup, M. (2007) Metabolomic Profiling of Rapid Cold Hardening and Cold Shock in Drosophila melanogaster. Journal of Insect Physiology, 53, 1218-1232. https://doi.org/10.1016/j.jinsphys.2007.06.012

[24] Colinet, H., Larvor, V., Laparie, M. and Renault, D. (2012) Exploring the Plastic Response to Cold Acclimation through Metabolomics. Functional Ecology, 26, 711-722. https://doi.org/10.1111/j.1365-2435.2012.01985.x

[25] Vilela, C.R., Teixeira, E.P. and Stein, C.P. (2001) Mosca-africana-do-figo, Zaprionus indianus (Diptera: Drosophilidae). In: Vilela, E.F., Zucchi, R.A. and Cantor, F., Eds., Histórico e impacto das pragas introduzidas no Brasil, Holos, Ribeirão Preto, 48-52.

[26] Parkash, R., Kalra, B. and Sharma, V. (2008) Changes in Cuticular Lipids, Water Loss and Desiccation Resistance in a Tropical Drosophilid: Analysis of Variation between and within Populations. Fly, 2, 189-197. https://doi.org/10.4161/fly.6619

[27] Bergman, I. and Loxley, R. (1970) New Spectrophotometric Method for the Determination of Proline in Tissue Hydrolyzates. Analytical Chemistry, 42, 702-706. https://doi.org/10.1021/ac60289a036

[28] Bradford, M.M. (1976) A Rapid and Sensitive Method for the Quantitation of Microgram Quantities of Protein Utilizing the Principle of Protein-Dye Binding. Analytical Biochemistry, 72, 248-254. https://doi.org/10.1016/0003-2697(76)90527-3

[29] Gibbs, A.G. (2002) Water Balance in Desert Drosophila: Lessons from Non-Charismatic Microfauna. Comparative Biochemistry and Physiology Part A: Molecular \& Integrative Physiology, 133, 781-789. https://doi.org/10.1016/S1095-6433(02)00208-8

[30] Mayntz, D., Raubenheimer, D., Salomon, M., Toft, S. and Simpson, S.J. (2005) Nutrient-Specific Foraging in Invertebrate Predators. Science, 307, 111-113. https://doi.org/10.1126/science.1105493

[31] Klepsatel, P., Gáliková, M., Xu, Y.J. and Kühnlein, R.P. (2016) Thermal Stress Depletes Energy Reserves in Drosophila. Scientific Reports, 6, Article No. 33667. https://doi.org/10.1038/srep33667

[32] Rall, B.C., Vucic-Pestic, O., Ehnes, R.B., Emmerson, M. and Brose, U. (2010) Temperature, Predator-Prey Interaction Strength and Population Stability. Global Change Biology, 16, 2145-2157. https://doi.org/10.1111/j.1365-2486.2009.02124.x

[33] Chen, Q.F., Ma, E., Behar, K.L., Xu, T. and Haddad, G.G. (2002) Role of Trehalose 
Phosphate Synthase in Anoxia Tolerance and Development in Drosophila melanogaster. Journal of Biological Chemistry, 277, 3274-3279. https://doi.org/10.1074/jbc.M109479200

[34] Kalra, B., Tamang, A.M. and Parkash, R. (2017) Cross-Tolerance Effects Due to Adult Heat Hardening, Desiccation and Starvation Acclimation of Tropical Drosophilid-Zaprionus indianus. Comparative Biochemistry and Physiology Part A: Molecular \& Integrative Physiology, 209, 65-73.

https://doi.org/10.1016/j.cbpa.2017.04.014

[35] Overgaard, J., Kristensen, T.N. and Sørensen, J.G. (2012) Validity of Thermal Ramping Assays Used to Assess Thermal Tolerance in Arthropods. PLoS ONE, 7, e32758. https://doi.org/10.1371/journal.pone.0032758

[36] Andersen, L.H., Kristensen, T.N., Loeschcke, V., Toft, S. and Mayntz, D. (2010) Protein and Carbohydrate Composition of Larval Food Affects Tolerance to Thermal Stress and Desiccation in adult Drosophila melanogaster. Journal of Insect Physiology, 56, 336-340. https://doi.org/10.1016/j.jinsphys.2009.11.006

[37] Yancey, P.H., Clark, M.E., Hand, S.C., Bowlus, R.D. and Somero, G.N. (1982) Living with Water Stress: Evolution of Osmolyte Systems. Science, 217, 1214-1222. https://doi.org/10.1126/science.7112124

[38] Crowe, J.H., Crowe, L.M. and Chapman, D. (1984) Preservation of Membranes in Anhydrobiotic Organisms: The Role of Trehalose. Science, 223, 701-703. https://doi.org/10.1126/science.223.4637.701

[39] Bursell, E. (1981) The Role of Proline in Energy Metabolism. In: Downer R.G.H., Ed., Energy Metabolism in Insects, Springer, Boston, 135-154.

https://doi.org/10.1007/978-1-4615-9221-1_5

[40] Hayat, S., Hayat, Q., Alyemeni, M.N., Wani, A.S., Pichtel, J. and Ahmad, A. (2012) Role of Proline under Changing Environments: A Review. Plant Signaling \& Behavior, 7, 1456-1466. https://doi.org/10.4161/psb.21949

[41] Krishnan, N., Dickman, M.B. and Becker, D.F. (2008) Proline Modulates the Intracellular Redox Environment and Protects Mammalian Cells against Oxidative Stress. Free Radical Biology and Medicine, 44, 671-681. https://doi.org/10.1016/j.freeradbiomed.2007.10.054

[42] Gäde, G. and Auerswald, L. (2002) Beetles' Choice-Proline for Energy Output: Control by AKHs. Comparative Biochemistry and Physiology Part B: Biochemistry and Molecular Biology, 132, 117-129. https://doi.org/10.1016/S1096-4959(01)00541-3

[43] Sacktor, B. and Childress, C.C. (1967) Metabolism of Proline in Insect Flight Muscle and Its Significance in Stimulating the Oxidation of Pyruvate. Archives of Biochemistry and Biophysics, 120, 583-588. https://doi.org/10.1016/0003-9861(67)90522-X

[44] Auerswald, L. and Gäde, G. (1995) Energy Substrates for Flight in the Blister Beetle Decapotoma lunata (Meloidae). The Journal of Experimental Biology, 198, 1423-1431. https://doi.org/10.1242/jeb.198.6.1423

[45] Auerswald, L. and Gäde, G. (1999) The Fate of Proline in the African Fruit Beetle Pachnoda sinuata. Insect Biochemistry and Molecular Biology, 29, 687-700. https://doi.org/10.1016/S0965-1748(99)00045-4

[46] Weeda, E. (1981) Hormonal Regulation of Proline Synthesis and Glucose Release in the Fat Body of the Colorado Potato Beetle, Leptinotarsa decemlineata. Journal of Insect Physiology, 27, 411-417. https://doi.org/10.1016/0022-1910(81)90020-2

[47] Bursell, E. (1977) Synthesis of Proline by Fat Body of the Tsetse Fly (Glossina morsitans): Metabolic Pathways. Insect Biochemistry, 7, 427-434. 
https://doi.org/10.1016/S0020-1790(77)90068-3

[48] Bursell, E. (1978) Quantitative Aspects of Proline Utilization during Flight in Tsetse Flies. Physiological Entomology, 3, 265-272.

https://doi.org/10.1111/j.1365-3032.1978.tb00158.x

[49] Weeda, E., De Kort, C.A.D. and Beenakkers, A.T. (1979) Fuels for Energy Metabolism in the Colorado Potato Beetle, Leptinotarsa decemlineata Say. Journal of Insect Physiology, 25, 951-955. https://doi.org/10.1016/0022-1910(79)90108-2

[50] Downer, R.G.H. and Matthews, J.R. (1976) Patterns of Lipid Distribution and Utilisation in Insects. American Zoologist, 16, 733-745.

https://doi.org/10.1093/icb/16.4.733

[51] Ko, L., Harshman, L., Hangartner, S., Hoffmann, A., Kachman, S. and Black, P. (2019) Changes in Lipid Classes of Drosophila melanogaster in Response to Selection for Three Stress Traits. Journal of Insect Physiology, 117, Article ID: 103890. https://doi.org/10.1016/j.jinsphys.2019.103890

[52] Akter, M.S., Siddique, S.S., Momotaz, R., Arifunnahar, M., Alam, K.M. and Mohiuddin, S.J. (2018) Biological Control of Insect Pests of Agricultural Crops through Habitat Management was Discussed. Journal of Agricultural Chemistry and Environment, 8, 1-13. https://doi.org/10.4236/jacen.2019.81001 